\title{
Melanocortin 4 Receptor-Mediated Hyperphagia and Activation of Neuropeptide Y Expression in the Dorsomedial Hypothalamus during Lactation
}

\author{
Peilin Chen, ${ }^{1,2}$ Sarah M. Williams, ${ }^{1}$ Kevin L. Grove, ${ }^{1}$ and M. Susan Smith ${ }^{1,2}$ \\ ${ }^{1}$ Division of Neuroscience, Oregon National Primate Research Center, and ${ }^{2}$ Department of Physiology and Pharmacology, Oregon Health and Science \\ University, Beaverton, Oregon 97006-3499
}

\begin{abstract}
In several hyperphagic models, including lactation, in which hypothalamic melanocortin signaling is reduced, a novel expression of NPY mRNA in the dorsomedial hypothalamus (DMH) has been observed, suggesting that melanocortin signaling and the induced NPY in the DMH may constitute unique neurocircuitry in mediating energy balance. Using lactating rats as a model, the present study first showed that in the DMH abundant $\alpha$-MSH and agouti-related protein fibers are in close apposition to NPY-positive cells. However, no NPY and MC4R (a melanocortin receptor) double-labeled neurons were observed. These data suggested that melanocortin input may synapse on presynaptic terminals that then synapse on DMH NPY cells. To study the function of DMH MC4Rs in energy balance, an MC3/4R-selective agonist, melanotan II (MTII), was injected bilaterally into the DMH. MTII injection significantly suppressed feeding induced by 24 hr fasting or suckling-induced hyperphagia. Furthermore, MTII treatment greatly attenuated suckling-induced NPY expression in the DMH. MTII treatment also stimulated uncoupling protein 1 activity in the brown adipose tissue of suckling female rats, indicative of increased sympathetic outflow. In summary, the present study demonstrated that the melanocortin system in the DMH not only plays an important role in inducing NPY expression in the DMH of lactating rats but also in regulating energy homeostasis, at least in part, by modulating appetite and energy expenditure.
\end{abstract}

Key words: NPY; MC4R; dorsomedial hypothalamus; lactation; food intake; UCP1

\section{Introduction}

Proopiomelanocortin (POMC) gene-derived peptides in the hypothalamus are a pivotal anorectic system in regulating energy balance. Central administration of $\alpha$-MSH, one of the POMC gene products, suppresses feeding and elevates energy expenditure (Cone, 1999; Vergoni and Bertolini, 2000), whereas POMC null mice develop overt obesity (Yaswen et al., 1999). In the hypothalamus, most POMC-producing neurons are found in the arcuate nucleus (ARH), and these neurons project into widespread brain regions, including the hypothalamus, septum, amygdala, and brainstem (Mezey et al., 1985).

Of the five melanocortin receptor subtypes for POMC peptides (Gantz and Fong, 2003), MC3R and MC4R are the two major subtypes found in the CNS, and MC4R is thought to be responsible for mediating the central effects of POMC peptides in energy homeostasis. For example, central administration of MC4R-specific antagonists causes an increase in feeding and obesity (Kask et al., 1998). Mice with MC4R deletion display hyperphagia, reduced energy expenditure, and obesity (Huszar et

Received Feb. 18, 2004; revised April 13, 2004; accepted April 16, 2004

This work was supported by National Institutes of Health Grants HD14643, RR00163, and HD18185. We thank Dr. X. Q. Xiao for helping develop the UCP1 mRNA real-time PCR assay and Dr. C. Li for comments on this manuscript. Correspondence should be addressed to Dr. M. Susan Smith, Oregon National Primate Research Center, Oregon Health and Science University, 505 Northwest 185th Avenue, Beaverton, OR 97006-3499. E-mail:smithsu@ohsu.edu. D01:10.1523/JNEUROSCI.0588-04.2004

Copyright $\odot 2004$ Society for Neuroscience $\quad 0270-6474 / 04 / 245091-10 \$ 15.00 / 0$ al., 1997). Moreover, overexpression of agouti-related protein (AGRP), an endogenous MC4R antagonist (Shutter et al., 1997), results in hyperphagia and obesity (Ollmann et al., 1997), further reinforcing the importance of MC4Rs in energy balance.

One underlying mechanism of the anorectic effects of MC4R action may involve the inhibition of hypothalamic NPY expression, a potent orexigenic system. In MC4R null mice, there is an induction of NPY mRNA in neurons in the dorsomedial hypothalamus (DMH) (Kesterson et al., 1997). Interestingly, neural activity of NPY neurons in the ARH is not altered in this obese model, despite the well documented role of ARH NPY neurons in feeding regulation (Levine and Morley, 1984). These results suggest that the hyperphagia associated with decreased MC4R action may involve induction of NPY expression in the DMH. Similar NPY expression in the DMH has been reported in two other hyperphagic models, lactation ( $\mathrm{Li}$ et al., 1998) and the dietinduced obese mouse (Guan et al., 1998). The characteristic of hyperphagia associated with these animal models has led to the hypothesis that NPY in the DMH may be involved in feeding regulation mediated by reduced MC4R signaling.

Lactation is a natural physiological state in which the energy expenditure attributable to milk production is met by a large increase in food intake [threefold to fourfold compared with nonlactating rats (Wade and Schneider, 1992; Wade et al., 1996; Brogan et al., 1999)]. Associated with the hyperphagia of lactation, the expression of the two orexigenic peptides in the ARH, 
NPY and AGRP, is elevated (Li et al., 1998; Chen et al., 1999), whereas the anorectic peptide, POMC, is reduced (Smith, 1993). Thus, lactating rats also exhibit reduced MC4R signaling as a consequence of reduced POMC and elevated AGRP expression, consistent with the notion that reduced melanocortin signaling is associated with the induction of NPY expression in the DMH ( $\mathrm{Li}$ et al., 1998).

In the present study, the lactating rat was used as a model to first determine the neuroanatomical relationship among POMC and AGRP nerve fibers and terminals, MC4R, and NPY neurons in the DMH. Second, a MC4R/MC3R agonist, melanotan II (MTII), was administered into the DMH to determine whether activation of MC4Rs in the DMH can suppress DMH NPY expression and food intake during lactation.

\section{Materials and Methods Animals and tissue}

Pregnant or cycling female Sprague Dawley rats (B \& K Universal, Kent, WA) were housed individually and maintained under a $12 \mathrm{hr}$ light/dark cycle (lights on at 7:00 A.M.) and constant temperature $\left(23 \pm 2^{\circ} \mathrm{C}\right)$. Food and water were provided ad libitum. The pregnant rats were checked for the birth of the pups every morning; the day of delivery was considered day 0 postpartum, and litters were adjusted to eight pups on day 2. All animal procedures were approved by the Oregon National Primate Research Center Institutional Animal Care and Use Committee.

For immunohistochemistry (IHC) studies, the animals were anesthetized with an overdose of pentobarbital ( $125 \mathrm{mg} / \mathrm{kg}$ body weight, i.p.) and perfused transcardially with $150 \mathrm{ml}$ of $2 \%$ sodium nitrite in saline, followed by $300 \mathrm{ml}$ of $4 \%$ borax-paraformaldehyde, $\mathrm{pH} 9.5$. The brain was removed, and $25 \mu \mathrm{m}$ sections were cut and collected in cryoprotectant and stored at $-20^{\circ} \mathrm{C}$ until use. For in situ hybridization (ISH) and real-time PCR studies, animals were killed by rapid decapitation. The brains and interscapular brown adipose tissue (IBAT) were removed quickly, frozen on powdered dry ice, and stored at $-80^{\circ} \mathrm{C}$. Coronal brain sections $(20 \mu \mathrm{m})$ were collected through the DMH/ARH areas and stored at $-80^{\circ} \mathrm{C}$ until use. Trunk blood was collected to assay plasma leptin levels by RIA.

\section{The distribution of melanocortin system peptides in the DMH and their anatomical relationship with DMH NPY neurons \\ IHC for $\alpha$-MSH or AGRP immunoreactivity}

To investigate whether ARH POMC or AGRP neurons sends fiber projections to the DMH area, single-label IHC for $\alpha$-MSH or AGRP was performed. A one-in-six series of $25 \mu \mathrm{m}$ tissue sections from three diestrous and three lactating animals and covering the entire rostral to caudal extent of the DMH was used for each antibody. Tissue sections were rinsed in $0.05 \mathrm{M}$ potassium PBS (KPBS), followed by treatment with $1 \% \mathrm{NaBH}_{4}-\mathrm{KPBS}$ solution. Sections were incubated in sheep anti- $\alpha$-MSH antibody (1:5000; Chemicon, Temecula, CA) or rabbit antiAGRP (1:5000; Phoenix Pharmaceuticals, Bont, CA) in KPBS with $0.4 \%$ Triton X-100 (KPBSX) for $48 \mathrm{hr}$. After incubation, the tissue was rinsed in KPBS and incubated in FITC-conjugated donkey anti-sheep or antirabbit IgG (1:300; Jackson ImmunoResearch, West Grove, PA) in KPBSX for $1 \mathrm{hr}$ at room temperature. The tissue sections were then mounted on gelatin-coated glass slides and coverslipped with buffered glycerol.

\section{Double-label ISH-IHC for NPY mRNA and $\alpha$-MSH, AGRP, or} NPY immunoreactivity

To investigate the anatomical relationship between melanocortin peptide fibers and DMH NPY neurons, double-label ISH-IHC was performed. Free-floating tissue sections (one-in-four series; covering the entire rostral to caudal extent of the DMH) from lactating D12 animals were used in this study. The NPY cRNA probe was made from a $511 \mathrm{bp}$ rat cDNA, into which digoxigenin (dig)-UTP (Roche Molecular Biochemicals, Indianapolis, IN) was incorporated (it should be noted that we could not use IHC to label NPY cell bodies because NPY immunore- activity (-ir) is not visible in hypothalamic cell bodies without colchicine treatment). The tissue sections were rinsed with sodium phosphate buffers, treated with a fresh solution containing $0.25 \%$ acetic anhydride in 0.1 M triethanolamine, $\mathrm{pH} 8.0$, followed by a rinse in $2 \times$ SSC. After the prehybridization wash, the free-floating sections were prehybridized in hybridization buffer containing $2 \mathrm{mg} / \mathrm{ml}$ torula yeast RNA for $2 \mathrm{hr}$ at $55^{\circ} \mathrm{C}$, followed by incubation in the hybridization buffer containing 2 $\mu \mathrm{g} / \mathrm{ml} \mathrm{dig-NPY} \mathrm{cRNA} \mathrm{for} 15 \mathrm{hr}$ at $55^{\circ} \mathrm{C}$. After incubation, the tissue sections were washed in SSC that increased in stringency, in RNase, in $0.1 \times \mathrm{SSC}$ at $60^{\circ} \mathrm{C}$, and then were incubated in a primary antibody mixture of mouse anti-dig monoclonal antibody IgG (1:10,000; Jackson ImmunoResearch) and one of the following antibodies: (1) sheep anti$\alpha$-MSH antibody IgG (1:5000; Chemicon); (2) rabbit anti-AGRP (1:5000; Phoenix Pharmaceuticals, Belmont, CA); or (3) rabbit anti-NPY (1:4000; provided by Dr. Phillip J. Larsen, Rheoscience, Rodovre, Denmark). When a double-label IHC and ISH was performed to detect AGRP-ir and NPY mRNA simultaneously, the AGRP antibody failed to detect AGRP-ir staining in the DMH in this particular procedure. Thus, NPY immunostaining was used to identify NPY-positive fibers as an alternative marker for AGRP-ir fibers. This is based on the findings that almost all ARH NPY neurons coexpress AGRP (Hahn et al., 1998; Chen et al., 1999). Furthermore, our laboratory has shown that the majority of NPY fibers in the DMH are also AGRP positive (Grove et al., 2003). Therefore, NPY-ir fiber staining is representative of AGRP, providing evidence of the neuroanatomical connections between AGRP-ir fibers and NPY neurons in the DMH. After incubation for $48 \mathrm{hr}$ at $4^{\circ} \mathrm{C}$, the tissue sections were washed and incubated in donkey biotinylated antimouse IgG (1:600) and donkey anti-sheep, anti-rabbit, or anti-goat IgG-tetramethylrhodamine isothiocyanate (1:300; Jackson ImmunoResearch) for $1 \mathrm{hr}$ at room temperature. This was followed by a $30 \mathrm{~min}$ incubation at room temperature in $\mathrm{ABC}$ solution (1:225, Vectastain $\mathrm{ABC}$ Elite kit; Vector Laboratories, Burlingame, CA), followed by application of biotinyl tyramide (1:200, TSA-Indirect kit; PerkinElmer Life Sciences, Boston, MA) for $15 \mathrm{~min}$. Finally, streptavidin-Cy2 (1:1000; $1 \mathrm{hr}$ at room temperature) was applied to the tissue sections to visualize mRNA encoding NPY. The tissue sections were then mounted on gelatin-coated glass slides, counterstained with Hoechst 33258 (Molecular Probes, Eugene, OR) for visualization of cell nuclei, and coverslipped with buffered glycerol.

\section{Confocal microscopy image analysis}

Close appositions between $\alpha$-MSH- or AGRP-positive fibers and DMH NPY neurons were analyzed with confocal laser scanning microscopy as described previously (Li et al., 1999). The TSC NT confocal system (Leica, Nussloch, Germany) consisted of an RBE inverted microscope (Leica) equipped with an Ar laser producing light at $467 \mathrm{~nm}$ and $488 \mathrm{~nm}$, a Kr laser for $568 \mathrm{~nm}$, and a HeNe laser for $647 \mathrm{~nm}$. Various objectives [ $25 \times /$ numerical aperture (NA) $0.75,40 \times / \mathrm{NA} 1.25$, and $100 \times / \mathrm{NA} 1.4$ ) were used to scan the images. A series of continuous optical sections, at $0.2 \mu \mathrm{m}$ intervals along the $z$-axis of a tissue section, were scanned for fluorescent signals. The signals obtained for each fluorophore on one series of optical sections were stored separately as a series of $512 \times 512$ pixel images. The stacks of individual optical slices $(0.2 \mu \mathrm{m}$ resolution) were analyzed using the MetaMorph imaging system (Universal Imaging, West Chester, PA) to determine the close appositions of melanocortin system fibers on the NPY neurons. The confocal images are presented as projections of a stack of optical images.

\section{Double-label ISH of dig-NPY and ${ }^{33} P-M C 4 R$ mRNAs}

Fresh frozen tissue sections from lactating D12 animals (20 $\mu \mathrm{m}$; one-inthree series) were used. A $600 \mathrm{bp}$ antisense rat MC4R cRNA probe was transcribed from the cDNA in which $25 \%$ of the UTP was ${ }^{33} \mathrm{P}$ labeled (PerkinElmer Life Sciences). The specific activity of the probe was $5-6 \times$ $10^{9} \mathrm{dpm} / \mu \mathrm{g}$. The same dig-NPY cRNA probe, as described above, was used in this study. Brain sections were fixed and washed as described above and were exposed to the mixture of ${ }^{33} \mathrm{P}-\mathrm{MC} 4 \mathrm{R}\left(5 \times 10^{7} \mathrm{cpm} / \mathrm{ml}\right)$ plus dig-NPY $(2 \mu \mathrm{g} / \mathrm{ml})$ cRNA probes in a moist chamber for $15 \mathrm{hr}$ at $55^{\circ} \mathrm{C}$. After incubation and posthybridization washes, slides were treated with a similar IHC protocol as described above, except that chromogen 
(DAB) was used to visualize NPY mRNA. The slides were air dried and dipped in NTB-4 emulsion (Eastman Kodak, Rochester, NY), exposed for $30 \mathrm{~d}$ at $4^{\circ} \mathrm{C}$, developed, counterstained with cresyl violet, and coverslipped with DPX mounting medium (BDH Chemicals, Poole, UK).

\section{Double-label ISH of dig-NPY and ${ }^{35} S-G A D^{67}$ mRNAs}

The same protocol for double-label ISH, as described above, was used. A $220 \mathrm{bp}$ antisense rat $\mathrm{GAD}^{67} \mathrm{cRNA}$ probe was transcribed from the cDNA in which $20 \%$ of the UTP was ${ }^{35} \mathrm{~S}$ labeled (PerkinElmer Life Sciences). The specific activity of the probe was $4-5 \times 10^{8} \mathrm{dpm} / \mu \mathrm{g}$. The slides were dipped and exposed to NTB- 4 emulsion for $7 \mathrm{~d}$.

\section{Effects of an MC4R agonist injected into the DMH on food intake, DMH NPY expression, and peripheral markers of energy metabolism \\ Bilateral cannulation of the DMH area}

Female rats were anesthetized with tribromoethanol $(20 \mathrm{mg} / 100 \mathrm{gm}$ body weight) and placed in a stereotaxic apparatus. The double-guide cannula (28 gauge; center-to-center, $1.0 \mathrm{~mm}$; tubing length below pedestal, $8.4 \mathrm{~mm}$; Plastics One, Roanoke, VA) was inserted into the area surrounding the compact zone of DMH [DMHp; coordinates: $3.3 \mathrm{~mm}$ caudal, $0.5 \mathrm{~mm}$ lateral to bregma, and $8.4 \mathrm{~mm}$ ventral to the dura, according to the atlas of Paxinos and Watson (1998)], the area containing a high density of suckling-activated NPY neurons. The guide cannula was secured to the skull by acrylic dental cement and anchored with stainlesssteel bone screws. A dummy cannula (32 gauge; tip extends $0.5 \mathrm{~mm}$ below the guide cannulas; Plastics One) was inserted into the guide cannula to maintain patency until the time of injections. Rats were handled daily during the recovery period, and only animals displaying normal food intake and weight gain after surgeries were used.

\section{MTII treatment paradigm}

Nonlactation groups. A group of eight cycling females were ovariectomized and implanted with a bilateral DMH cannula $8 \mathrm{~d}$ before the MTII (Phoenix Pharmaceuticals, Mountain View, CA) treatment. The rat chow was removed from the animals $24 \mathrm{hr}$ before the treatment. On the day of treatment, freely moving rats were remotely injected at 9:00 A.M. with MTII $(0.3 \mathrm{nmol}$ in $0.4 \mu \mathrm{l}$ per side per animal; $n=4)$ or vehicle [0.4 $\mu$ l double-filtered sterile artificial CSF $(\mathrm{aCSF} ; n=4)$ through the internal cannula (32 gauge; tip extended $0.5 \mathrm{~mm}$ below the guide cannula) that was connected via PE50 tubing to a Hamilton syringe. Injected solutions were manually pushed through over a 1 min period, and the internal cannula stayed in situ for $1 \mathrm{~min}$ after the injection. Immediately after injections, preweighted rat chow was placed in cages. The dose of MTII was extrapolated from the literature as causing a maximal suppression of food intake when given intracerebroventricularly or directly into specific brain nuclei (Fan et al., 1997). Food intake was measured 2, 4, 8, and 24 $\mathrm{hr}$ after injection. After the completion of the experiment, animals were killed by decapitation. The brains were collected, sectioned, and counterstained with thionin to verify the placements of guide cannulas.

Lactation groups. The acute suckling paradigm was used to induce DMH NPY expression. Sixteen lactating animals with eight-pup litters were implanted with bilateral DMH cannulas on day 2 postpartum, and the animals were returned to their litters to resume suckling and to recuperate from the surgery. At 6:30 P.M. on day 9 postpartum, litters were separated from their dams and placed with foster animals until $6 \mathrm{hr}$ before the MTII injection. After $48 \mathrm{hr}$ of pup separation, the dams received bilateral injections of MTII ( $n=8 ; 0.4 \mathrm{nmol}$ in $0.4 \mu$ l per side) or vehicle ( $n=8 ; 0.4 \mu \mathrm{l}$ of double-filtered sterile aCSF per side). Pups were returned to the animals immediately after the injection to resume suckling for $9 \mathrm{hr}$. A $9 \mathrm{hr}$ acute suckling stimulus was chosen based on preliminary studies showing that $9 \mathrm{hr}$ of suckling was sufficient to induce near maximal expression of NPY mRNA in the DMH while minimizing alterations in energy expenditure attributable to milk production. Thus, in this acute suckling paradigm, the expression of NPY in the DMH is primarily the result of neural stimulation induced by suckling. Animals had ad libitum access to food and water during the experiment. The interactions between the dams and the pups were observed during the first $15 \mathrm{~min}$ and the last $15 \mathrm{~min}$ of the $9 \mathrm{hr}$ suckling period. Most dams started retrieving and suckling their pups within 3 min of returning the litter. During the last $15 \mathrm{~min}$ of the suckling period, most dams were observed to be in the kyphosis suckling position. To ensure that suckling and milk production occurred, each of the eight pups' bellies was dissected and graded $0-3$, depending on the amount of the contents (24 would be the maximum score for an eight-pup litter). The food intake of each dam was measured at the end of the $9 \mathrm{hr}$ period of resuckling. Brain tissue, BAT, and trunk blood were collected. Brain tissue was sectioned (20 $\mu \mathrm{m}$ coronal sections) and then subjected to ISH for NPY mRNA

To ensure that alteration of DMH NPY expression was a direct result of the MTII treatment and not secondary to the feeding-suppressive effect of MTII, another group of 16 lactating animals (8 received MTII injections, 8 received vehicle injections) were subjected to the same experiment paradigm, except that during the $9 \mathrm{hr}$ period of resuckling, animals had no access to food but ad libitum access to water. Our preliminary studies showed that animals receiving $9 \mathrm{hr}$ of acute suckling in the absence of food expressed a comparable intensity of DMH NPY mRNA as fed animals.

\section{ISH to detect DMH NPY mRNA}

The same rat NPY cRNA and ISH procedures as described above were used, except that the NPY cDNA probe was labeled with ${ }^{35} \mathrm{~S}-\mathrm{UTP}$. The specific activity of the probe was $5-6 \times 10^{8} \mathrm{dpm} / \mu \mathrm{g}$, and the saturating concentration for the probe used in the assay was $0.3 \mu \mathrm{g} / \mathrm{ml} \cdot \mathrm{kb}$.

\section{Quantification of DMH NPY mRNA}

Only animals with the cannula necrosis tracks within the DMH boundary were used for the analysis. Brain sections containing DMH were used for the NPY mRNA analysis (20 $\mu \mathrm{m}$; one-in-three coronal sections). Tissue sections from all groups were processed in one batch to avoid interassay variations. For data analysis, the brain sections were anatomically matched across animals from all groups. The hybridization signals were quantitated using the OPTIMUS image analysis system, version 6.2 (Media Cybernetics, Silver Spring, MD). Brain section images were captured individually by a CCD camera (Cohu, San Diego, CA) and displayed on a computer monitor. The system identified silver grains by the brightness of the image. An estimate for silver grains over the entire $\mathrm{DMH}$ on each tissue section was given as the area occupied by silver grains within the region of interest (ROI). The brightness, threshold, and ROI were kept constant for all the sections analyzed. A ROI was drawn to encompass all the NPY-positive neurons in the DMH. However, because the NPY neurons were scattering around the compact zone, it was not possible to exclude the compact zone, where low levels of NPY mRNA were present in both lactating and nonlactating animals. Therefore, another ROI was drawn to outline the compact zone, and the silver grain area within was analyzed and subtracted from the readout obtained from the ROI that covered the whole DMH, so that silver grain clusters associated only with NPY neurons were counted. The sum of the silver grain area was divided by number of sections quantified for each animal and was expressed as silver grain area per section.

\section{Statistical analysis}

The data were expressed as the area occupied by grains per section. The mean area occupied by grains per section was determined for each animal. Because all of the slides could not be processed in one assay, the results were normalized to the vehicle-treated controls. Data are presented as the means \pm SEM. Differences between groups were evaluated using one-way ANOVA and post hoc Fisher's tests. Differences were considered significant if $p<0.05$.

\section{Real-time PCR assay for uncoupling protein expression in BAT}

BAT was homogenized in TRIzol reagent (Invitrogen, Carlsbad, CA), and total cellular RNA was isolated according to the manufacturer's specifications. The quality and completeness of the RNA were determined by nanoassay bioanalysis using the 2100 Bioanalyzer (Agilent, Foster City, CA) and measuring the area under the curve of the peaks corresponding to $18 \mathrm{~S}$ and $28 \mathrm{~S}$ rRNA. The concentration of the RNA was determined by measuring the absorbance at 260 and $280 \mathrm{~nm}$. Real-time quantitative PCR amplification reactions were performed in an ABI Prism 7700 se- 
quence detection system (Applied Biosystems, Foster City, CA) to measure uncoupling protein 1 (UCP1) mRNA levels. The principle of TaqMan real-time PCR is based on DNA amplification and cleavage of an internal probe that is hybridized to the amplified DNA by the $5^{\prime}-3^{\prime}$ exonuclease activity of the TaqDNA polymerase during PCR cycles. RNA samples were prepared for real-time PCR by random-primed reverse transcription reaction using random hexamer primers (Promega, Madison, WI) and $1 \mu \mathrm{g}$ of RNA. The final concentration of the reverse transcriptase product was determined by measuring the absorbance at 260 and $280 \mathrm{~nm}$. The reaction was then diluted to $10 \mathrm{ng} / \mu \mathrm{l}$ for PCR analysis. Reactions were conducted in duplicate for increased accuracy. Ten microliters of reaction mixture contained $5 \mu$ l of TaqMan Universal PCR Master Mix, 300 nM specific target gene primers, $80 \mathrm{~nm}$ glyceraldehyde-3-phosphate dehydrogenase (GAPDH) gene primers, $250 \mathrm{~nm}$ specific probes, and $2 \mu \mathrm{l}(20 \mathrm{nM})$ of cDNA. The amplification was performed as follows: $2 \mathrm{~min}$ at $50^{\circ} \mathrm{C}, 10 \mathrm{~min}$ at $95^{\circ} \mathrm{C}$, then 40 cycles each at $95^{\circ} \mathrm{C}$ for $15 \mathrm{sec}$ and $60^{\circ} \mathrm{C}$ for $60 \mathrm{sec}$ in the ABI/Prism 7700 Sequence Detector system. After PCR was completed, baseline and threshold values were set to optimize the amplification plot, and the data were exported to an Excel spreadsheet. Standard curves were drawn on the basis of the log of the input RNA versus the critical threshold (CT) cycle, which is the cycle in which the fluorescence of the sample was greater than the threshold of baseline fluorescence. These standard curves allowed for the CT values to be converted to relative RNA concentration for each sample. The primers and probes were designed using the Primer Express software (Applied Biosystems). The sequence of the primer and probes used was: UCP1: forward TCCCTCAGGATTGGCCTCTAC, reverse GTCATCAAGCCAGCCGAGAT, probe Fam-AACGCCTGCCTCTTTGGGAAGCAA-Tamra; GAPDH: forward AGAACATCATCCCTGCATCCA, reverse GGCCATGCCAGTGAGCTT, probe Vic-TGGTGCCAAGGCTGTGGGCAA-Tamra.

\section{RIA for serum leptin}

Serum leptin levels were determined with a commercial leptin RIA kit (Linco Research, St. Charles, MO). The range of standard concentrations was between 0.5 and $50 \mathrm{ng} / \mathrm{ml}$, which is within the limit of linearity. All samples were measured in the same assay.

\section{Results}

Neuroanatomical connections between AGRP, $\alpha$-MSH fibers, and NPY neurons in the DMH

IHC and ISH techniques were used to establish the neuroanatomical relationship between melanocortin-producing neuronal projections (AGRP, $\alpha$-MSH) and DMH NPY neurons. Analysis of single-label IHC demonstrated that there was abundant $\alpha$-MSH-ir (Fig. 1a) and AGRP-ir (Fig. 2a) fiber staining throughout the DMH area of the lactating rats. To investigate the anatomical relationship between the melanocortin peptides and suckling-activated NPY neurons in the DMH, we applied doublelabel fluorescent histological staining to simultaneously label the fibers and NPY cell bodies. The double-label fluorescent IHCISH technique was sensitive enough to stain a comparable amount of $\alpha$-MSH-ir fibers (red) as was detected with singlelabel IHC, and NPY mRNA-containing neurons (green) were observed scattering around the DMHp (Fig. 1b). With the aid of confocal microscopy, many close appositions were observed between $\alpha$-MSH-ir fibers and NPY neurons. An examination of 0.2 $\mu \mathrm{m}$ single optical sections through each NPY neuron confirmed the close apposition of $\alpha$-MSH-ir fibers with the cell bodies (Fig. $1 c, d)$. In the AGRP-ir/NPY mRNA double IHC-ISH studies, AGRP-ir was represented by NPY-ir. As shown in Figure $2 b$, we observed robust NPY-ir fibers and NPY mRNA staining in the $\mathrm{DMH}$. When examined under higher magnification, many close appositions between NPY-ir fibers and NPY neurons were found, and the close appositions were confirmed after examining a series of $0.2 \mu \mathrm{m}$ confocal optical sections.
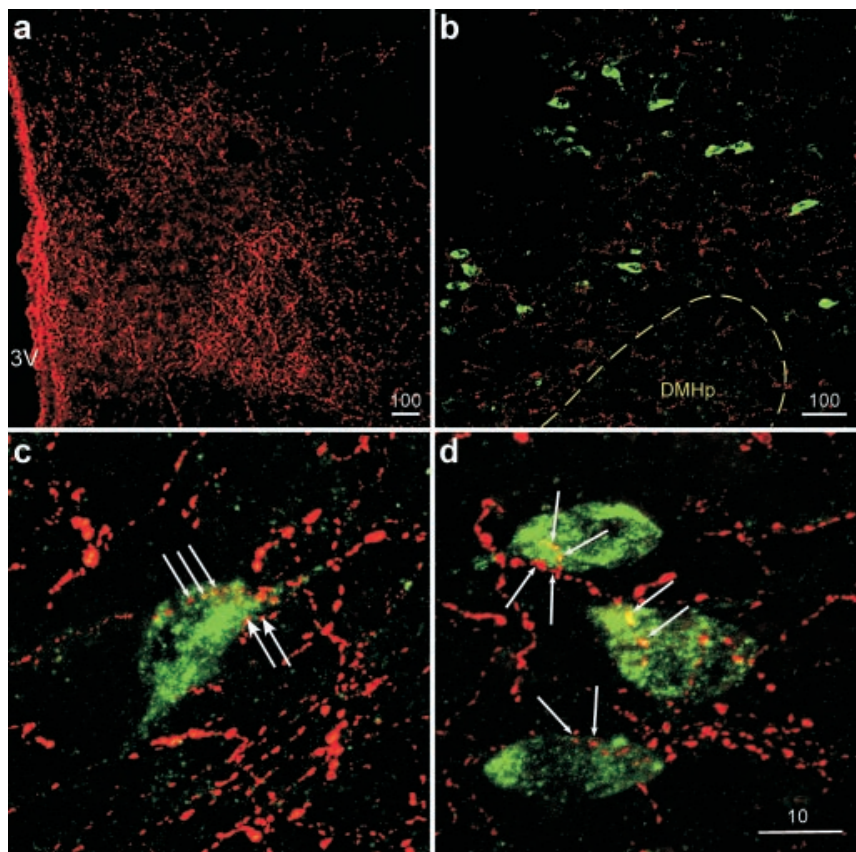

Figure 1. Localization of NPY mRNA (green) and $\alpha$-MSH-ir (red) fibers in the DMH. $a$, Lowpower stacked confocal images showing abundant single labeling of $\alpha$-MSH-ir fibers in the DMH. 3V, Third ventricle. $b$, Many NPY mRNA-containing neurons (green) were found scattering outside the compact zone of DMH (DMHp; dotted line). $c, d$, Representative high-magnification confocal images showing NPY mRNA (green) and $\alpha$-MSH-ir (red) fibers in the DMH. Close appositions (arrows) of $\alpha$-MSH-ir fibers on NPY neurons were observed in this area. The scale bars represent micrometers.

\section{MC4R and NPY mRNA expression in the DMH}

These studies examined the relationship between the melanocortin signaling system, MC4R, and DMH NPY neurons. Doublelabel ISH of MC4R and NPY was examined with dark-field and bright-field microscopy. In the DMH area, both MC4R (silver grain clusters) (Fig. 3a,c) and NPY (brown cytoplasmic staining) (Fig. 3b,d) neurons were scattering next to each other, outside of the DMHp; however, no colocalization of the two substances was observed. To ensure that the lack of coexpression was not attributable to decreased sensitivity of the double-label ISH technique, other brain regions were examined in which both MC4R and NPY were found. Examples of neurons coexpressing MC4R and NPY were observed in the cortical area (Fig. $3 e, f$ ).

\section{$\mathrm{GAD}^{67}$ and NPY mRNA expression in the DMH}

These studies examined the anatomical relationship between GABAergic and NPY neurons in the DMH. Double-label ISH of $\mathrm{GAD}^{67}$ and NPY was examined with dark-field and bright-field microscopy. In the DMH area, both $\mathrm{GAD}^{67}$ (silver grain clusters) (Fig. $3 g$ ) and NPY (brown cytoplasmic staining) (Fig. 3h) neurons were scattering next to each other outside of the DMHp. However, no colocalization of the two substances was observed. To ensure that the lack of coexpression was not attributable to decreased sensitivity of the double-label ISH technique, ARH NPY neurons, the majority of which have been shown to be GABAergic (Horvath et al., 1997), were examined. Figure $3 i$ shows several examples of GAD ${ }^{67} / \mathrm{NPY}$ double-labeled neurons in the ARH.

Effect of DMH MTII injection on the refeeding response of 24 $\mathrm{hr}$ food-deprived nonlactating female rats

The effects of MTII were first examined in nonlactating animals to determine whether direct injections into the $\mathrm{DMH}$ and the 

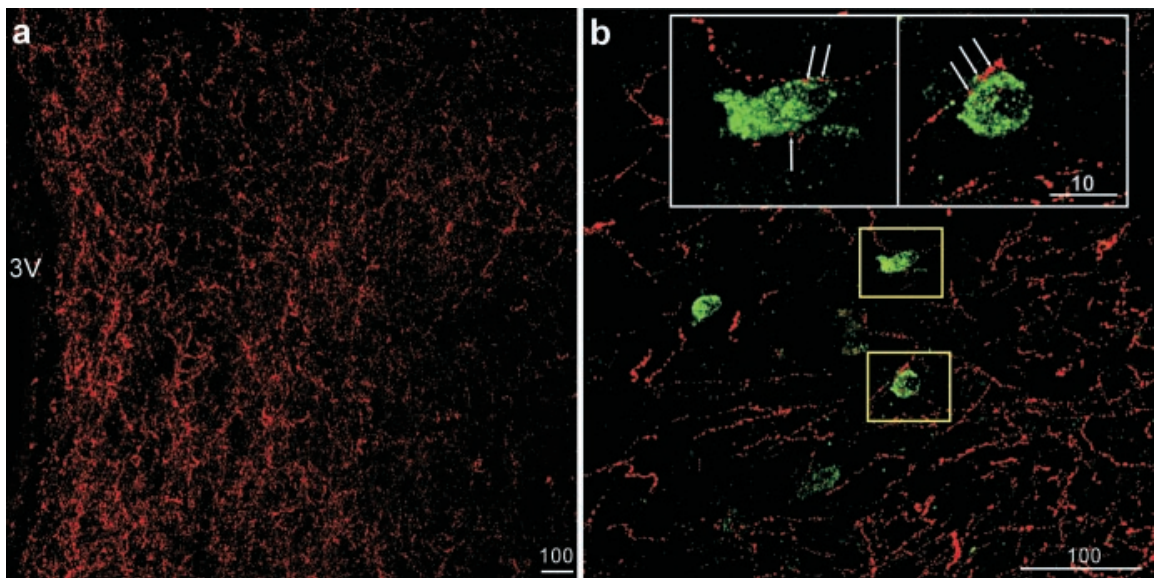

Figure 2. a, Low-power stacked confocal images showing abundant single labeling of AGRP-ir fibers in the DMH. 3V, Third ventricle. $b$, Many NPY mRNA-containing neurons (green) were surrounded by NPY-ir fibers (red) in the DMH. The insets are high-magnification confocal images of the yellow-boxed areas showing NPY-ir fibers (red) in close apposition (arrows) to NPYproducing neurons in the DMH. The scale bars represent micrometers.

dose of MTII were effective in suppressing food intake. The refeeding response after a $24 \mathrm{hr}$ fast was used to maximize food intake in the vehicle-treated animals. Bilateral administration of MTII into the DMH after a $24 \mathrm{hr}$ period of fasting produced a significant inhibition of food intake at all time points measured when compared with the vehicle treatment (Fig. 4). The suppressive effect of MTII on the refeeding response seems to be long lasting, because the cumulative food intake consumed by the MTII-treated group was still significantly lower than that of the vehicle-treated animals $24 \mathrm{hr}$ after the drug infusion (Fig. 4).

\section{Effect of DMH MTII injection on food intake and DMH NPY expression in lactating rats}

Having established the effectiveness of the MTII treatment, an acute suckling paradigm was used to examine the effects of increased melanocortin signaling in the DMH on suckling-induced hyperphagia and induction of NPY expression. Rats receiving vehicle or MTII injections into the DMH exhibited normal maternal behavior. When eight-pup litters were returned to the injected animals, they retrieved the pups and started suckling within $3 \mathrm{~min}$. After $9 \mathrm{hr}$ of suckling, the stomach contents of pups from MTII and vehicle groups were examined and found to not be different (vehicle, 19.71 \pm 1.40 ; MTII, 16.25 \pm 2.02 ; $p=0.09$ ), indicating a similar level of milk ingestion by the pups. The vehicle-treated lactating animals consumed $\sim 13$ gm of rat chow in the $9 \mathrm{hr}$ time period. The hyperphagic effects of the suckling stimulus were already in evidence because animals that received no suckling stimulus after a $48 \mathrm{hr}$ pup separation ate only $\sim 56 \%$ of the amount of food consumed by acute resuckled rats during a similar 9 hr period. Suckled animals receiving bilateral DMH MTII injections ate significantly less than the vehicle-injected suckled animals in the same period of time (74\% decrease) (Fig. 5d).

Suckling eight pups for $9 \mathrm{hr}$ induced the expression of NPY in a population of neurons located around the compact zone in the DMH (Fig. 5a). This expression pattern was comparable with that found in animals resuckled for $24 \mathrm{hr}$ or during chronic lactation ( $\mathrm{Li}$ et al., 1998). In animals receiving MTII treatment, DMH NPY mRNA was 33\% of the level observed in the vehicletreated animals ( $p<0.05$, respectively) (Fig. 5b,c). It should be noted that the low levels of NPY mRNA signal observed in the DMHp did not change in response to treatment.
Suckling eight pups for $9 \mathrm{hr}$ in the absence of food induced a comparable intensity of DMH NPY mRNA expression as was observed in the ad libitum fed group. Treatment with MTII caused approximately a $70 \%$ reduction of NPY mRNA expression compared with the vehicletreated animals $(p<0.05)$. There was no difference in stomach contents of the pups between the vehicle- and MTII-treated groups (vehicle, $15.67 \pm 2.50 ;$ MTII, $15.33 \pm 2.20 ; p=0.46$ ), indicating a similar level of milk ingestion by the pups.

\section{Effect of DMH MTII administration on} the IBAT UCP1 gene expression in the lactating rats

It has been shown that central injection of an MC4R agonist activates a host of peripheral responses to increase energy expenditure, including increases in oxygen consumption (Hwa et al., 2001), sympathetic outflow to BAT, (Haynes et al., 1999), UCP1 mRNA expression (Williams et al., 2003), and core body temperature (Murphy et al., 2000). In addition, the DMH has been implicated in playing a key role in regulating sympathetic activity and thermogenesis. To provide additional information of the effects of MTII injections in the DMH, UCP1 mRNA levels in IBAT were used as a marker for changes in peripheral energy metabolism. Figure $6 a$ shows the standard curves of UCP1 and GAPDH RNA, which serves as a reference standard to normalize the DNA quality and quantity among different samples. Along the five serial 10-fold dilutions, both tested genes showed linear amplification within the range used for this study, with correlation coefficients $>0.99$.

Animals suckling eight pups for $9 \mathrm{hr}$ had significantly lower UCP1 mRNA in the BAT than nonlactating females (nonlactating females, $0.63 \pm 0.16$; acute resuckled, $0.25 \pm 0.03$ relative units; $n=7$ for both groups; $p<0.05$ ), similar to that described previously (Xiao et al., 2004). In animals resuckled for $9 \mathrm{hr}$ in the presence of food, bilateral MTII injections into the DMH prevented the suckling-induced suppression of UCP1 activity in the BAT (Fig. 6b) and restored levels to those observed in nonlactating females. In contrast, MTII failed to prevent the sucklinginduced suppression in UCP1 mRNA in BAT in lactating rats suckling for $9 \mathrm{hr}$ in the absence of food (Fig. $6 c$ ).

\section{Effect of DMH MTII administration on plasma leptin levels in the lactating rats}

Serum leptin measurements were made to obtain another measure of the effects of MTII administration on peripheral signals of energy metabolism. Our previous studies showed that lactating rats have markedly decreased serum leptin levels, and removal of the suckling stimulus for $48 \mathrm{hr}$ results in leptin levels that are much higher than normal, reflecting the increased body fat of lactating animals (Brogan et al., 1999; Xiao et al., 2004). Compared with the results obtained in our previous study, the leptin levels $(2.8 \pm 0.5 \mathrm{ng} / \mathrm{ml}$ ) (Table 1$)$ in animals receiving $9 \mathrm{hr}$ of acute suckling after $2 \mathrm{~d}$ of pup removal were lower than animals receiving no acute suckling stimulus $(\sim 4.5 \mathrm{ng} / \mathrm{ml})$ but not as suppressed as levels observed in chronic lactating rats $(\sim 0.4 \mathrm{ng} /$ $\mathrm{ml})$. These data suggest that animals receiving $9 \mathrm{hr}$ of suckling were still in the process of adjusting their peripheral physiological responses to adapt to the negative energy balance associated with 
prolonged milk production. Rats suckling for $9 \mathrm{hr}$ in the absence of food exhibited significantly lower plasma leptin levels than the ad libitum-fed lactating rats ( $\mathrm{Ta}$ ble 1). DMH MTII injections resulted in a modest reduction of plasma leptin levels in both the ad libitum and food-deprived groups; however, the differences were not statistically significant (Table 1). It has been suggested that the sympathetic nervous system exerts an inhibitory control over leptin production and release (Donahoo et al., 1997); Pierroz et al. (2002) observed a significant downregulation of plasma leptin levels in mice receiving $4 \mathrm{~d}$ of intracerebroventricular MTII treatment, but not in the pair-fed controls. These results might explain why we failed to see a significant effect of MTII on circulating leptin levels of resuckled animals after only 9 hr of MTII treatment.

\section{Discussion}

In the present study, we used an acute resuckling paradigm as a model to determine whether MC4Rs in the DMH play an important role in (1) the regulation of food intake and energy expenditure, particularly under conditions in which there is a strong hyperphagia, such as lactation, and (2) the activation of NPY expression in the DMH during lactation. The short suckling duration $(9 \mathrm{hr}$ ) used in the study reflects, to a greater extent, the neural effects of suckling and, to a lesser extent, the state of negative energy balance that comes from long-term milk production. This conclusion is supported by the results showing that leptin levels in animals receiving $9 \mathrm{hr}$ of suckling were not suppressed to the same level as those of chronic lactating rats. The additional reduction in serum leptin levels in fooddeprived suckled animals provides additional support for the notion that leptin levels are a good indicator of the degree of negative energy balance.

In agreement with other studies (Mezey et al., 1985; Haskell-Luevano et al., 1999), we found intense $\alpha$-MSH and AGRP fibers and terminals within the DMH area. The close apposition of $\alpha$-MSH fibers with NPY neurons in the $\mathrm{DMH}$ provides a neuroanatomical framework for melanocortin peptides to affect NPY expression. At this time, it is not possible to provide an empirical estimation of the relative contribution of ARH-derived $\alpha$-MSH fibers identified in the DMH. In addition to the ARH, POMC/ $\alpha$-MSH-producing neurons are also found in the nucleus of the solitary tract (Palkovits et al., 1987; Bronstein et al., 1992). However, $\mathrm{DMH}$ retrograde studies have shown that the majority of inputs to the DMH arise in the hypothalamus, with only a few projections from the brainstem (Thompson and Swanson, 1998; Chen and Smith, 2003). Therefore, it is reasonable to conclude that POMC
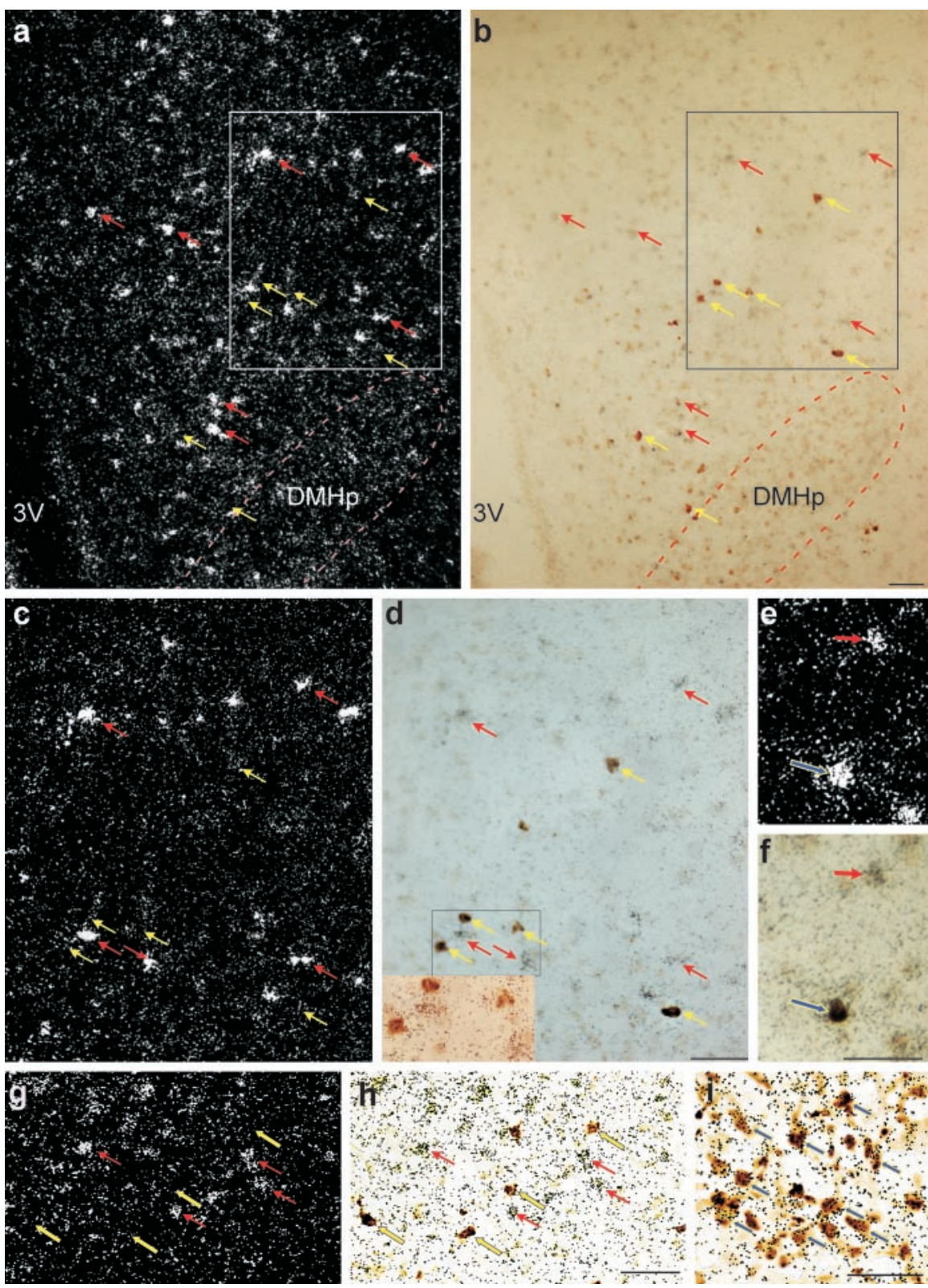

Figure 3. Expression of MC4Rs, GAD ${ }^{67}$, and NPY mRNA in the rat brain. $a, b$, Low-power dark-field ( $a$ ) and bright-field ( $b$ ) photomicrographs of DMH showing the distribution of MC4Rs (silver grain clusters, red arrows) and NPY neurons (brown cytoplasmic deposit, yellow arrows) scattering next to each other around the compact zone of DMH (DMHp). No apparent colocalization between the two signals was observed in this area. $3 \mathrm{~V}$, Third ventricle. $c, d$, High-power photomicrographs of the boxed areas in $a$ and $b$ to further illustrate that no colocalization of MC4R and NPY was found in the DMH. The inset in $d$ depicts the highmagnification bright-field photomicrograph of the area delineated by the black rectangle in $d$. $e$ and $f$ show an example of MC4Rand NPY-coexpressing neurons (indicated by the blue arrows) identified in the cerebral cortex. $g, h$, Low-power dark-field $(g)$ and bright-field ( $h$ ) photomicrographs of DMH showing GAD ${ }^{67}$ mRNA-positive neurons (brown cytoplasmic deposit, yellow arrows). Note that little colocalization was observed between the two signals in the DMH. $i$, Low-power brightfield photomicrograph of the ARH showing that the majority of NPY neurons (brown cytoplasmic deposit, indicated by the blue arrows) coexpressed GAD ${ }^{67}$ (clusters of black speckles, indicated by the blue arrows). Scale bars, $100 \mu \mathrm{m}$.

neurons in the ARH are the major source of $\alpha$-MSH fiber projections to the DMH that come in close apposition to NPY neurons.

Similarly, it is not possible to directly determine the relative input of ARH-derived NPY-AGRP fibers to the DMH. Some of the NPY fibers could be originating locally from DMH NPY cells. In addition, NPY-producing neurons in the ventrolateral medulla have been shown to send modest projections to the $\mathrm{DMH}$ area (Allen et al., 1983; Thompson and Swanson, 1998; Chen and Smith, 2003). Therefore, it remains possible that some of the 


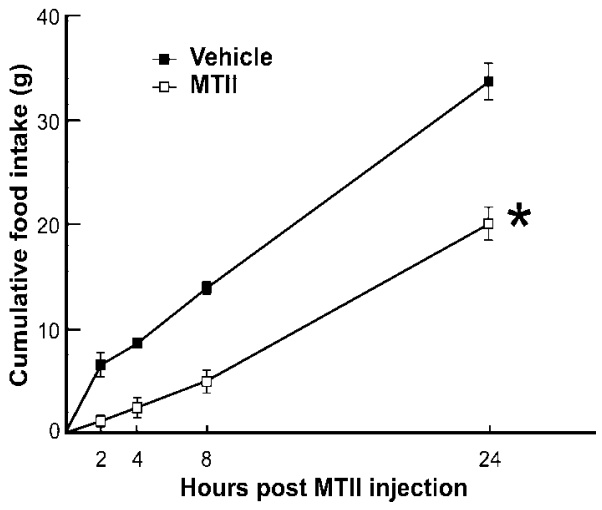

Figure 4. Bilateral DMH administration of MTII suppresses feeding. MTII $(0.4 \mathrm{nmol})$ injected directly to the DMH of $24 \mathrm{hr}$ food-deprived ovariectomized rats produced a potent inhibition of cumulative food intake (grams; mean $\pm \mathrm{SEM} ; n=4$ for each group) compared with vehicle control. ${ }^{*} p<0.05$, significantly different from vehicle-treated rats at all time points.

NPY-ir fibers making close appositions on DMH NPY neurons might come from NPY cells other than ARH. Taken together, these results provide a neuroanatomical framework for $\alpha$-MSH and AGRP effects on NPY neurons in the DMH.

In the present study, we failed to detect NPY/MC4R doublelabeled cells in the DMH. This is not surprising because most studies have demonstrated that MC4Rs couple with $\mathrm{G}_{\mathrm{s}}$ to activate adenylyl cyclase (Cone et al., 1996). Thus, one would predict that activation of MC4R results in increased cell activity, which is opposite to our hypothesis that decreased melanocortin system signaling during lactation causes increased DMH NPY neuronal activity. A likely explanation of the anatomical results is that MC4Rs may be expressed on a separate population of neurons within the $\mathrm{DMH}$, which in turn make local synapses onto $\mathrm{DMH}$ NPY neurons. These presynaptic terminals that express MC4Rs may be the actual targets of the $\alpha$-MSH and AGRP projections (Fig. 7). Thus, the melanocortin peptides may synapse on the inhibitory terminals that impinge on the NPY neurons. During lactation, the decreased melanocortin system signaling could result in reduced inhibitory input to the NPY neurons, leading to activation of NPY expression (Fig. 7). GABA is the prime candidate for the inhibitory input to the DMH NPY neurons, because we and others have reported there are abundant GABA neurons in the DMH (Okamura et al., 1990). In addition, the results from double ISH of GAD ${ }^{67}$ and NPY indicate that, like MC4Rs, GABA is not coexpressed with NPY but GABA neurons are in the vicinity of the NPY neurons in the DMH. In addition, $\alpha$-MSH has been shown to modulate its downstream effectors via presynaptic GABAergic inputs in the paraventricular nucleus (PVH) (Cowley et al., 1999). A demonstration of colocalization of GABA and MC4R in the DMH would provide additional support for this hypothesis.

To further substantiate the physiological significance of the anatomical link between the ARH melanocortin system and DMH NPY neurons, MTII, an MC3R/MC4R receptor agonist, was injected directly into the $\mathrm{DMH}$ of both nonlactating and lactating rats to examine (1) whether DMH is a target of POMC through MC4R in modulating appetite and energy homeostasis and (2) whether reversal of reduced melanocortin tone in the $\mathrm{DMH}$ of lactating rats would prevent the activation of NPY neurons in the DMH. In agreement with others (Kim et al., 2000), the present study first showed that bilateral injections of MTII into the DMH of ovariectomized nonlactating rats significantly attenuated the $24 \mathrm{hr}$ fasting-induced refeeding. One possible down-
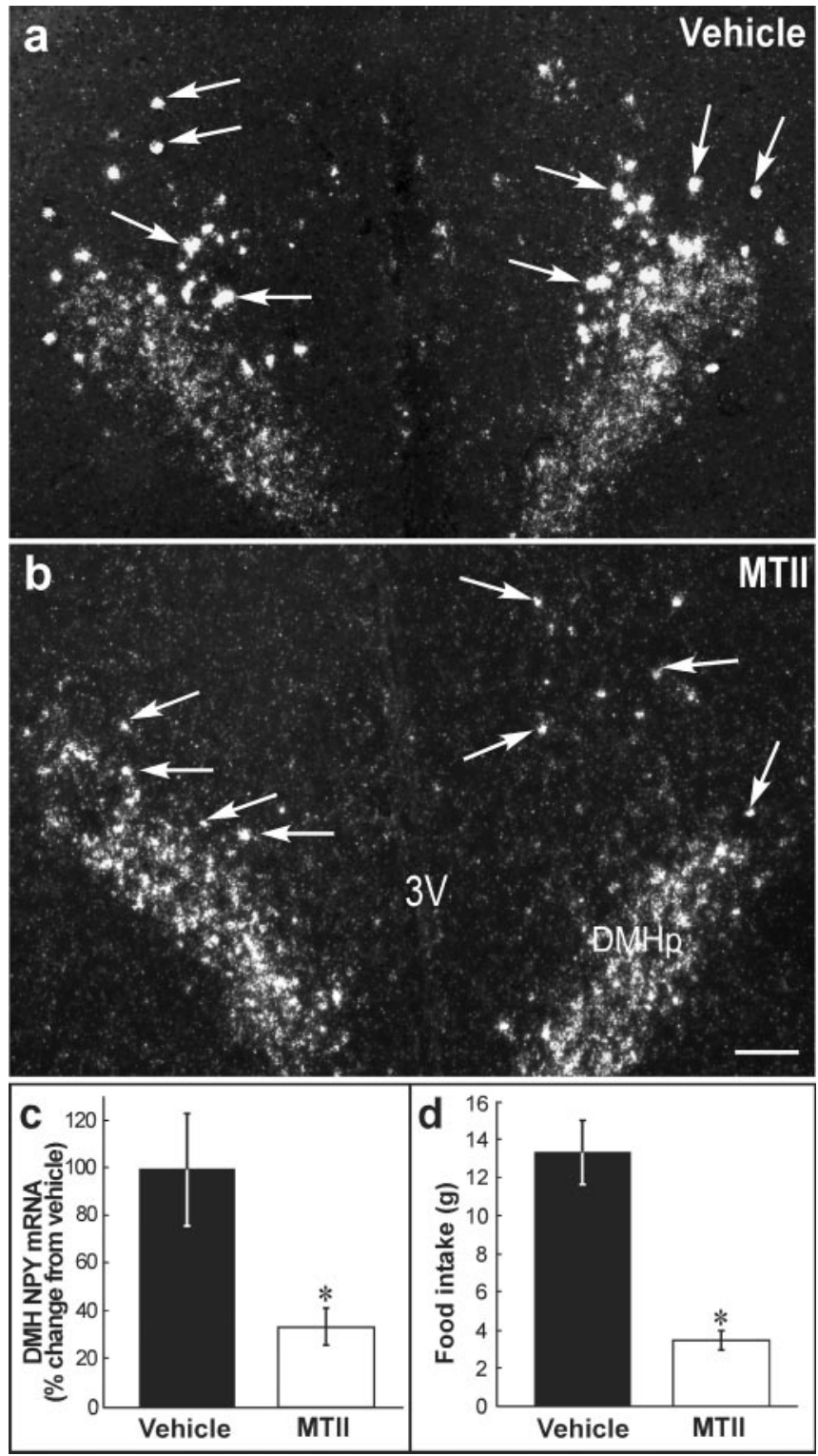

Figure 5. Bilateral MTII administration into the DMH suppresses suckling-induced DMH NPY expression and hyperphagia in the lactating rats. $a$, Representative dark-field photomicrograph showing the expression of NPY mRNA in the DMH area from a lactating rat treated with vehicle. Suckling for $9 \mathrm{hr}$ induced prominent NPY silver grain clusters (representative clusters indicated by the arrows) scattered in the DMH. $b$, DMH MTII injection resulted in a reduction in both number and size of the silver grain clusters (several examples indicated by the arrows). The low level of signal covering the DMHp was observed in all the animals examined. c, Quantitative analysis of DMH NPY expression levels in the vehicle- and MTIl-treated groups. d, Summary of accumulative food intake of animals treated with vehicle or MTII. MTII-treated lactating rats ate significantly less than the vehicle-treated group. Data were expressed as means \pm SEM. ${ }^{*} p<$ 0.05 , significantly different from vehicle-treated group. 3V: third ventricle. Scale bar, $200 \mu \mathrm{m}$

stream target of the DMH that is mediating this effect is the $\mathrm{PVH}$, because the DMH projects heavily to the parvicellular part of the PVH (Thompson et al., 1996), which is a final common pathway through which the brain controls feeding (Swanson and Sawchenko, 1983). Although extensive studies have suggested a direct pathway from ARH POMC neurons to MC4R-expressing cells in the PVH to suppress feeding (Vergoni and Bertolini, 2000), our findings suggest yet an additional pathway for ARH POMC peptides to regulate feeding, by way of the MC4R in the $\mathrm{DMH}$. This indirect pathway may allow the POMC system to fine-tune its final output to PVH to regulate appetite. 


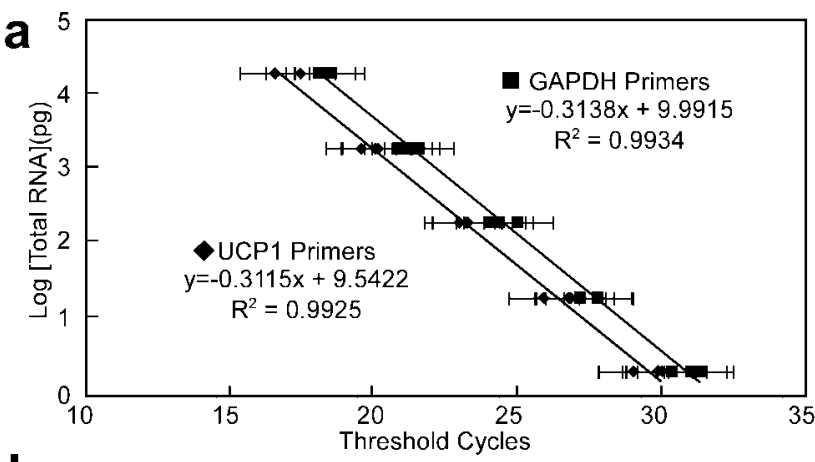

b

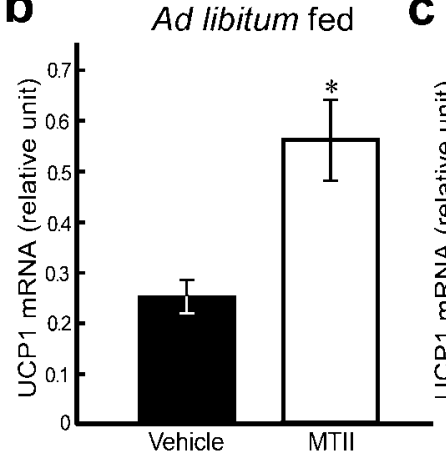

C

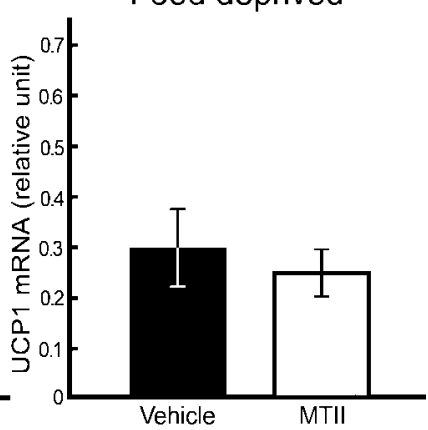

Figure 6. UCP1 mRNA expression in the IBAT. $a$, The standard curves of UCP1 ( $\bullet$ ) and GAPDH $(\square)$ for real-time PCR. GAPDH was selected as a reference standard to normalize the RNA quality and quantity from IBAT across different groups. $b$, Bilateral DMH MTII administration significantly stimulated IBAT UCP1 mRNA expression in the ad libitum-fed lactating rats. MTII injection caused approximately a 128\% increase of UCP1 mRNA expression compared with the vehicle group. c, Direct DMH MTII injections to the food-deprived lactating rats did not alter UCP1 mRNA expression in the IBAT when compared with the vehicle-treated rats. ${ }^{*} p<0.05$, significantly different from vehicle group.

Table 1. Plasma leptin levels in lactating rats receiving bilateral injections of MTII or vehicle to the DMH

\begin{tabular}{lll}
\hline & Leptin $(\mathrm{ng} / \mathrm{ml})$ & \\
\cline { 2 - 3 } & Vehicle $(n=7)$ & MTII $(n=8)$ \\
\hline Ad libitum fed & $2.81 \pm 0.50^{*, * * *}$ & $2.07 \pm 0.43^{*, * * * *}$ \\
Food deprived & $1.27 \pm 0.32^{* *, * * *}$ & $0.74 \pm 0.25^{* *, * * * *}$ \\
\hline${ }^{*} p=0.11 ;{ }^{* *} p=0.11 ;{ }^{* * *} p=0.01 ;{ }^{* * * *} p=0.01$. &
\end{tabular}

Using the acute resuckling model, the present study showed that $9 \mathrm{hr}$ of resuckling was sufficient to not only induce hyperphagia but also to induce DMH NPY expression. This short period of resuckling is not sufficient to increase NPY expression in the ARH (Li et al., 1998), suggesting that the induction of NPY expression in the DMH is an important component of the hyperphagia of lactation. Activation of MC4Rs by direct injection of MTII in the DMH of lactating rats greatly decreased (by 77\%) the suckling-induced increase in food intake. The MTII-induced decrease in food intake was coupled with a greatly attenuated expression of suckling-induced DMH NPY mRNA (Fig. 5). The similar reduction of DMH NPY expression by the MTII treatment, whether the animals were fed or not fed during the $9 \mathrm{hr}$ period of acute suckling, suggests that the reduction was a direct result of the DMH MTII injections and not secondary to the inhibitory effect of the MTII treatment on feeding. It is noteworthy that MTII treatment was equally effective in suppressing food intake in nonlactating females that lack NPY expression in neurons in the DMH. This result suggests that the appetite circuitry involving $\mathrm{DMH}$ exerts a tonic input into the PVH to modulate daily energy intake. When a large energy demand is present, such as milk production, NPY expression in the DMH will provide an additional signal to the PVH to further increase food intake. This view is supported by the findings from Crowley et al. (2003) showing that heightened NPY expression and lowered MC4R signaling is the main driving force for the hyperphagia in lactation. This study showed that central injections of a NPY antagonist and $\alpha$-MSH (at a dose much higher than normally used to suppress feeding in normal female rats) reduced food intake of lactating rats to $\sim 40 \%$ of normal. Their results are in agreement with our finding that when the extra population of NPY neurons in the DMH was suppressed by the activation of MC4Rs in the $\mathrm{DMH}$, food intake of the lactating rats was significantly reduced by $77 \%$, indicating that DMH NPY neuronal population plays a key role in inducing hyperphagia during lactation. Recently, Hill and Levine (2003) showed that lactating mice lacking functional NPY were still able to mount a comparable hyperphagia as the wild-type controls, which seems to undermine the importance of NPY in feeding during lactation. However, the apparent normal feeding regulation in the NPY knock-out mice could be a result of the developmental compensation by other redundant systems or that the nonselective loss of NPY throughout the brain may not be an accurate reflection of the role of the DMH NPY system in feeding under certain circumstances such as lactation. The results obtained in the present studies clearly showed that DMH NPY plays a pivotal role in modulating lactation-associated hyperphagia.

In the present study, we showed that direct DMH MTII injections prevented the suckling-induced reduction of IBAT UCP1 mRNA in the ad libitum-fed resuckled rats. This result demonstrates for the first time that MC4R signaling in the $\mathrm{DMH}$ is involved in regulating sympathetic outflow to the BAT. There are several possible pathways by which MC4R in the DMH may modulate UCP1 expression in the BAT. First, the information may be relayed via projections to the PVH that in turn influence sympathetic neuronal activity that innervates BAT. Second, DMH sends modest projections to the medullary nucleus raphé pallidus (Thompson et al., 1996), an area shown to be the essential integration area mediating the thermogenic response in rodent models (Madden and Morrison, 2003). Finally, it has been shown that BAT UCP1 gene expression can be regulated by thyroid hormones (Masaki et al., 2000); therefore, it is possible the DMH MC4R-responsive pathway may regulate thyrotropinreleasing hormone neuronal activity in the $\mathrm{PVH}$, which in turn modulates UCP1 gene expression in the BAT via releasing thyroid hormones. Furthermore, Fekete et al. (2002) showed NPY in the PVH can suppress the hypothalamic-pituitary-thyroid axis and intracerebroventricular infusion of NPY greatly decreased the expression of UCP1 in the BAT (Zakrzewska et al., 1999). Taken together, it is conceivable that MTII in the DMH might stimulate UCP1 gene production in the BAT via its suppression of DMH NPY output to the PVH. However, the same MTII treatment to the food-deprived lactating group did not prevent the reduction in UCP1 mRNA expression in the BAT, although NPY mRNA in the DMH was decreased. These data suggest that the combination of energy expenditure (milk production) and no energy intake (fasting) may activate protective energy adaptations to prevent additional energy loss and thus override the effect of DMH MTII treatment in activating UCP1 activity in the BAT.

In conclusion, the present study provides a neuroanatomical framework for the action of the melanocortin signaling system in the DMH. The melanocortin system in the DMH not only plays an important role in inducing NPY expression in the DMH of 


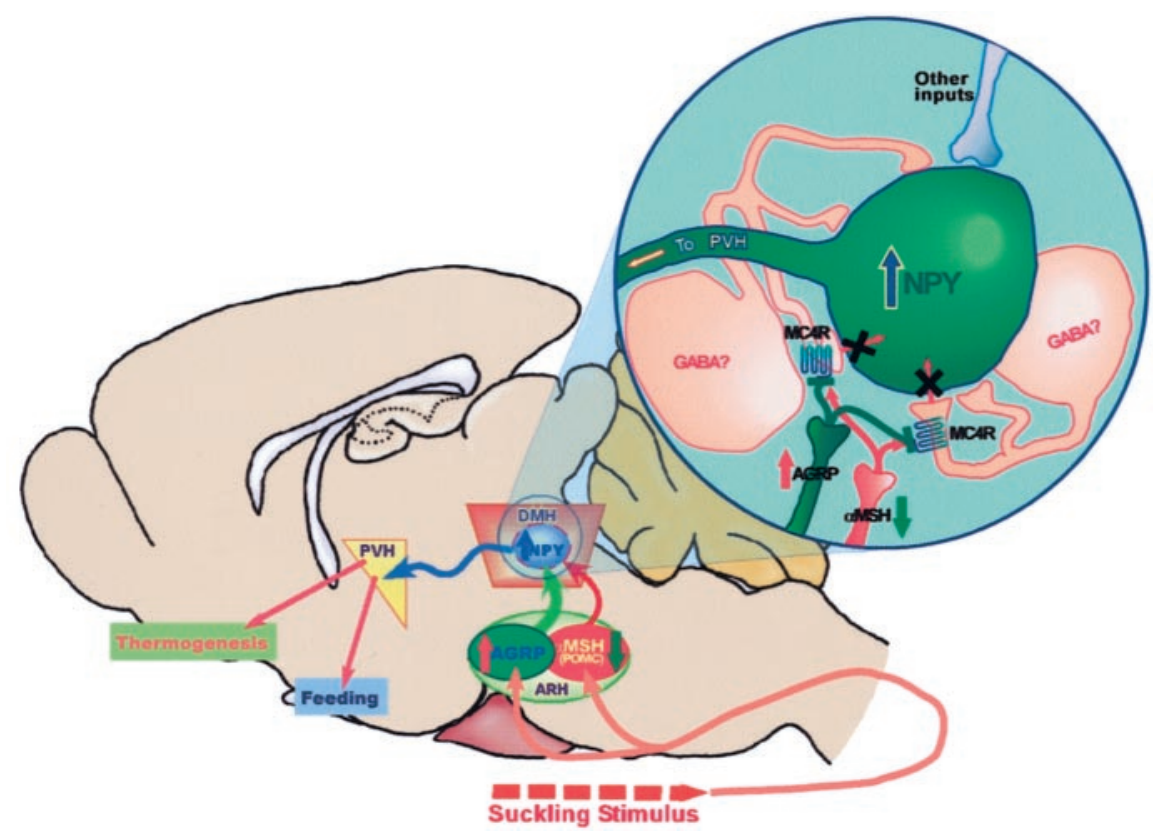

Figure 7. Schematic diagram summarizes the proposed hypothesis for MC4R-mediated activation of DMH NPY neurons and the hyperphagic response during lactation. During lactation, ARH AGRP/NPY input into the DMH is elevated whereas ARH POMC tone into the DMH is reduced. Most of these inputs likely terminate on inhibitory interneurons expressing MC4R (i.e., GABAergic) in the DMH. The inset depicts MC4R signaling. The increased AGRP input in combination with reduced POMC input from the ARH causes a reduction in MC4R signaling, leading to a decrease in GABAergic inhibition on the DMH NPY neurons, resulting in the activation of NPY mRNA expression during lactation. The activated NPY neurons in the DMH may be involved in a number of modulations during lactation, including hyperphagia and energy expenditure, probably via projection to the PVH.
Fan W, Boston BA, Kesterson RA, Hruby VJ, Cone RD (1997) Role of melanocortinergic neurons in feeding and the agouti obesity syndrome. Nature 385:165-168.

Fekete C, Sarkar S, Rand WM, Harney JW, Emerson $\mathrm{CH}$, Bianco AC, Beck-Sickinger A, Lechan RM (2002) Neuropeptide Y1 and Y5 receptors mediate the effects of neuropeptide $\mathrm{Y}$ on the hypothalamic-pituitary-thyroid axis. Endocrinology 143:4513-4519.

Gantz I, Fong TM (2003) The melanocortin system. Am J Physiol Endocrinol Metab 284:E468-E474.

Grove KL, Allen S, Grayson BE, Smith MS (2003) Postnatal development of the hypothalamic neuropeptide Y system. Neuroscience 116:393-406.

Guan XM, Yu H, Trumbauer M, Frazier E, Van der Ploeg LH, Chen H (1998) Induction of neuropeptide $\mathrm{Y}$ expression in dorsomedial hypothalamus of diet-induced obese mice. NeuroReport 9:3415-3419.

Hahn TM, Breininger JF, Baskin DG, Schwartz MW (1998) Coexpression of Agrp and NPY in fasting-activated hypothalamic neurons. Nat Neurosci 1:271-272.

Haskell-Luevano C, Chen P, Li C, Chang K, Smith MS, Cameron JL, Cone RD (1999) Characterization of the neuroanatomical distribution of agouti-related protein immunoreactivity in the rhesus monkey and the rat. Endocrinology 140:1408-1415.

Haynes WG, Morgan DA, Djalali A, Sivitz WI, Mark AL (1999) Interactions between the melanocortin system and leptin in control of sympathetic nerve traffic. Hypertension 33:542-547.

lactating rats but also in regulating energy homeostasis, at least in part by modulating appetite and energy expenditure.

\section{References}

Allen YS, Adrian TE, Allen JM, Tatemoto K, Crow TJ, Bloom SR, Polak JM (1983) Neuropeptide Y distribution in the rat brain. Science 221:877-879.

Brogan RS, Mitchell SE, Trayhurn P, Smith MS (1999) Suppression of leptin during lactation: contribution of the suckling stimulus versus milk production. Endocrinology 140:2621-2627.

Bronstein DM, Schafer MK, Watson SJ, Akil H (1992) Evidence that betaendorphin is synthesized in cells in the nucleus tractus solitarius: detection of POMC mRNA. Brain Res 587:269-275.

Chen P, Smith MS (2003) Suckling-induced activation of neuronal input to the dorsomedial nucleus of the hypothalamus: possible candidates for mediating the activation of DMH neuropeptide Y neurons during lactation. Brain Res 984:11-20.

Chen P, Li C, Haskell-Luevano C, Cone RD, Smith MS (1999) Altered expression of agouti-related protein and its colocalization with neuropeptide $\mathrm{Y}$ in the arcuate nucleus of the hypothalamus during lactation. Endocrinology 140:2645-2650.

Cone RD (1999) The central melanocortin system and energy homeostasis. Trends Endocrinol Metab 10:211-216.

Cone RD, Lu D, Koppula S, Vage DI, Klungland H, Boston B, Chen W, Orth DN, Pouton C, Kesterson RA (1996) The melanocortin receptors: agonists, antagonists, and the hormonal control of pigmentation. Recent Prog Horm Res 51:287-318.

Cowley MA, Pronchuk N, Fan W, Dinulescu DM, Colmers WF, Cone RD (1999) Integration of NPY, AGRP, and melanocortin signals in the hypothalamic paraventricular nucleus: evidence of a cellular basis for the adipostat. Neuron 24:155-163.

Crowley WR, Ramoz G, Hurst B (2003) Evidence for involvement of neuropeptide $\mathrm{Y}$ and melanocortin systems in the hyperphagia of lactation in rats. Pharmacol Biochem Behav 74:417-424.

Donahoo WT, Jensen DR, Yost TJ, Eckel RH (1997) Isoproterenol and somatostatin decrease plasma leptin in humans: a novel mechanism regulating leptin secretion. J Clin Endocrinol Metab 82:4139-4143.
Hill JW, Levine JE (2003) Abnormal response of the neuropeptide Y-deficient mouse reproductive axis to food deprivation but not lactation. Endocrinology 144:1780-1786.

Horvath TL, Bechmann I, Naftolin F, Kalra SP, Leranth C (1997) Heterogeneity in the neuropeptide Y-containing neurons of the rat arcuate nucleus: GABAergic and non-GABAergic subpopulations. Brain Res 756:283-286.

Huszar D, Lynch CA, Fairchild-Huntress V, Dunmore JH, Fang Q, Berkemeier LR, Gu W, Kesterson RA, Boston BA, Cone RD, Smith FJ, Campfield LA, Burn P, Lee F (1997) Targeted disruption of the melanocortin-4 receptor results in obesity in mice. Cell 88:131-141.

Hwa JJ, Ghibaudi L, Gao J, Parker EM (2001) Central melanocortin system modulates energy intake and expenditure of obese and lean Zucker rats. Am J Physiol Regul Integr Comp Physiol 281:R444-R451.

Kask A, Rago L, Mutulis F, Pahkla R, Wikberg JE, Schioth HB (1998) Selective antagonist for the melanocortin 4 receptor (HS014) increases food intake in free-feeding rats. Biochem Biophys Res Commun 245:90-93.

Kesterson RA, Huszar D, Lynch CA, Simerly RB, Cone RD (1997) Induction of neuropeptide $\mathrm{Y}$ gene expression in the dorsal medial hypothalamic nucleus in two models of the agouti obesity syndrome. Mol Endocrinol 11:630-637.

Kim MS, Rossi M, Abusnana S, Sunter D, Morgan DG, Small CJ, Edwards CM, Heath MM, Stanley SA, Seal LJ, Bhatti JR, Smith DM, Ghatei MA, Bloom SR (2000) Hypothalamic localization of the feeding effect of agouti-related peptide and alpha-melanocyte-stimulating hormone. Diabetes 49:177-182.

Levine AS, Morley JE (1984) Neuropeptide Y: a potent inducer of consummatory behavior in rats. Peptides 5:1025-1029.

Li C, Chen P, Smith MS (1998) The acute suckling stimulus induces expression of neuropeptide Y (NPY) in cells in the dorsomedial hypothalamus and increases NPY expression in the arcuate nucleus. Endocrinology 139:1645-1652.

Li C, Chen P, Smith MS (1999) Morphological evidence for direct interaction between arcuate nucleus neuropeptide Y (NPY) neurons and gonadotropin-releasing hormone neurons and the possible involvement of NPY Y1 receptors. Endocrinology 140:5382-5390. 
Madden CJ, Morrison SF (2003) Excitatory amino acid receptor activation in the raphe pallidus area mediates prostaglandin-evoked thermogenesis. Neuroscience 122:5-15.

Masaki T, Yoshimatsu H, Sakata T (2000) Expression of rat uncoupling protein family mRNA levels by chronic treatment with thyroid hormone. Int J Obes Relat Metab Disord 24[Suppl 2]:S162-S164.

Mezey E, Kiss JZ, Mueller GP, Eskay R, O’Donohue TL, Palkovits M (1985) Distribution of the pro-opiomelanocortin derived peptides, adrenocorticotrope hormone, alpha-melanocyte-stimulating hormone and betaendorphin (ACTH, alpha-MSH, beta-END) in the rat hypothalamus. Brain Res 328:341-347.

Murphy B, Nunes CN, Ronan JJ, Hanaway M, Fairhurst AM, Mellin TN (2000) Centrally administered MTII affects feeding, drinking, temperature, and activity in the Sprague-Dawley rat. J Appl Physiol 89:273-282.

Okamura H, Abitbol M, Julien JF, Dumas S, Berod A, Geffard M, Kitahama K, Bobillier P, Mallet J, Wiklund L (1990) Neurons containing messenger RNA encoding glutamate decarboxylase in rat hypothalamus demonstrated by in situ hybridization, with special emphasis on cell groups in medial preoptic area, anterior hypothalamic area and dorsomedial hypothalamic nucleus. Neuroscience 39:675-699.

Ollmann MM, Wilson BD, Yang YK, Kerns JA, Chen Y, Gantz I, Barsh GS (1997) Antagonism of central melanocortin receptors in vitro and in vivo by agouti-related protein. Science 278:135-138.

Palkovits M, Mezey E, Eskay RL (1987) Pro-opiomelanocortin-derived peptides (ACTH/beta-endorphin/alpha-MSH) in brainstem baroreceptor areas of the rat. Brain Res 436:323-338.

Paxinos G, Watson C (1998) The rat brain in stereotaxic coordinates, Ed 4. New York: Academic Press.

Pierroz DD, Ziotopoulou M, Ungsunan L, Moschos S, Flier JS, Mantzoros CS (2002) Effects of acute and chronic administration of the melanocortin agonist MTII in mice with diet-induced obesity. Diabetes 51:1337-1345.

Shutter JR, Graham M, Kinsey AC, Scully S, Luthy R, Stark KL (1997) Hy- pothalamic expression of ART, a novel gene related to agouti, is upregulated in obese and diabetic mutant mice. Genes Dev 11:593-602.

Smith MS (1993) Lactation alters neuropeptide-Y and proopiomelanocortin gene expression in the arcuate nucleus of the rat. Endocrinology 133:1258-1265.

Swanson LW, Sawchenko PE (1983) Hypothalamic integration: organization of the paraventricular and supraoptic nuclei. Annu Rev Neurosci 6:269-324.

Thompson RH, Swanson LW (1998) Organization of inputs to the dorsomedial nucleus of the hypothalamus: a reexamination with Fluorogold and PHAL in the rat. Brain Res Brain Res Rev 27:89-118.

Thompson RH, Canteras NS, Swanson LW (1996) Organization of projections from the dorsomedial nucleus of the hypothalamus: a PHA-L study in the rat. J Comp Neurol 376:143-173.

Vergoni AV, Bertolini A (2000) Role of melanocortins in the central control of feeding. Eur J Pharmacol 405:25-32.

Wade GN, Schneider JE (1992) Metabolic fuels and reproduction in female mammals. Neurosci Biobehav Rev 16:235-272.

Wade GN, Schneider JE, Li HY (1996) Control of fertility by metabolic cues. Am J Physiol 270:E1-E19.

Williams DL, Bowers RR, Bartness TJ, Kaplan JM, Grill HJ (2003) Brainstem melanocortin $3 / 4$ receptor stimulation increases uncoupling protein gene expression in brown fat. Endocrinology 144:4692-4697.

Xiao XQ, Grove KL, Grayson BE, Smith MS (2004) Inhibition of uncoupling protein expression during lactation: role of leptin. Endocrinology 145:830-838.

Yaswen L, Diehl N, Brennan MB, Hochgeschwender U (1999) Obesity in the mouse model of pro-opiomelanocortin deficiency responds to peripheral melanocortin. Nat Med 5:1066-1070.

Zakrzewska KE, Sainsbury A, Cusin I, Rouru J, Jeanrenaud B, RohnerJeanrenaud F (1999) Selective dependence of intracerebroventricular neuropeptide Y-elicited effects on central glucocorticoids. Endocrinology 140:3183-3187. 